\title{
No limite da realidade: intervenção psicoterapêutica na vivência de João
}

\author{
On the edge of reality: Psychotherapeutic \\ intervention in João's experience
}

\author{
Vânia FREITAS ${ }^{1}$ \\ Catarina Pinheiro MOTA ${ }^{1}$ \\ Marisa BORGES 2
}

\begin{abstract}
Resumo
O presente estudo de caso aborda a problemática inerente à vivência de João, com 55 anos de idade, pautada por um padrão de angústia diante do passado e de intolerância com o presente. Percebe-se uma ansiedade permanente que traduz a tomada da consciência latente do conflito que permanece entre o eu e sua experiência real. O conhecimento da sua vivência atual adivinha uma organização de personalidade esquizoide em que acresce uma depressividade significativa com ideação suicida frequente. A intervenção psicoterapêutica tem o objetivo de facilitar o crescimento pessoal e integrar as transformações pessoais, as exigências sociais e as expectativas futuras do paciente. O método utilizado foi direcionado para a livre expressão dos seus sentimentos numa perspectiva de intervenção enquadrada na Abordagem Centrada na Pessoa. Os resultados revelam uma crescente libertação pessoal, marcada pela expressão de sentimentos e maior aceitação de si. Evidenciou-se, ao longo do processo, uma maior adaptação psicossocial por parte do paciente.
\end{abstract}

Palavras-chave: Apoio social; Depressão; Transtorno da personalidade esquizoide; Transtorno depressivo.

\begin{abstract}
This case study discusses the problems inherent in the experience of a 55 year old man, evidenced by a pattern of distress faced with the past and intolerance toward the present. A permanent anxiety was evident that translated into a latent awareness of the conflict between the self and his real experience. The knowledge of his actual experience indicated a schizoid personality organization with significant depressivity and frequent suicidal ideation. The psychotherapeutic intervention was designed with the aim of facilitating personal growth and integrating personal transformation, social demands and the future expectations of the patient. The Methodological procedures used were directed toward the free expression of his feelings from the perspective of an intervention based on the Person Centered Aproach. The results reveal a growing process of personal liberation evidenced by the expression of feelings and greater self-acceptance. Throughout the psycotherapeutic process higher psychossocial adaptation of the patient was evidenced.
\end{abstract}

Keywords: Social support; Depression; Schizoid personality disorder; Depressive disorder

$\checkmark v \nabla v$

1 Universidade de Trás-os-Montes e Alto Douro, Centro Integrado de Formação de Professores, Departamento de Educação e Psicologia. R. Dr. Manuel Cardona, Apartado 1013, 5001-558, Vila Real, Portugal. Correspondência para/Correspondence to: V. FREITAS. E-mail: <vania_rnt@hotmail.com>.

2 Psicóloga. Vila Real, Portugal. 
O presente trabalho compõe uma análise de estudo de caso original que se reporta ao processo terapêutico de um homem de 55 anos de idade, que apresenta uma vivência ansiosa e um padrão de angústia que cria uma incongruência interna e interfere no seu bem-estar psicológico diário. O processo terapêutico foi iniciado devido a um pedido explícito do paciente e a uma avaliação psicológica que destacou um conflito latente entre o eu ideal e sua experiência real. A avaliação destaca uma organização de personalidade esquizoide com uma depressividade significativa com ideação suicida frequente. A personalidade esquizoide de João é marcada pela dificuldade nos relacionamentos interpessoais e ausência emocional, e por estar distante da aprovação dos demais, da crítica ou de sentimentos alheios. A patologia traduz um cariz de introversão na vivência autorreferenciada, ao que se associam má socialização e desajuste emocional com tendência à solidão e estados distímicos (Váldes, 2000). A esse processo acresce-se a depressividade, que pode corresponder a uma depressão crônica latente ou larvada, com traços de personalidade associados à baixa autoestima, à culpabilidade, à vulnerabilidade à perda, à tendência à adinamia e à idealização do passado (Matos, 2007). Foi traçado um plano de intervenção à luz da Abordagem Centrada na Pessoa, com objetivo de ajudá-lo, diante do conflito patente, na aceitação de si e na organização interna do seu self.

\section{Identificação e enquadramento}

João (nome fictício) estava desempregado, tinha 55 anos de idade e morava na zona rural, no concelho de Vila Real, no norte de Portugal. Atualmente está casado e tem uma filha de 23 anos. João vem à consulta de psicologia clínica sozinho, apresenta-se pouco cuidado e aparenta ser mais velho do que é. Denota uma postura marcadamente retraída, inibida, acompanhada pela ausência de contato ocular. Oriundo de uma família tradicional, João vive presentemente com dificuldades financeiras significativas. Não aceitando esse fato, culpabiliza-se constantemente por não conseguir presentear uma vida melhor a sua família, uma vez que em momentos anteriores apresentou condições financeiras que o deixaram satisfeito, nomeadamente quando da sua primeira emigração para a Suíça.

Em casa, sua relação familiar é descrita como inconstante, fato que atribui ao seu estado de humor oscilante; ele não percebe a família como um refúgio, pelo que, ao invés disso, prefere permanecer sozinho nos dias que está mais triste e "ir para os campos falar com os animais" (sic). Desta feita, a relação conjugal é distante, pautada pela presença de conflitos. Entretanto, a relação com a filha é descrita como forte, fruto do sentimento muito prevalecente do pai em relação a ela, e, de acordo com João, tal sentimento é recíproco. No entanto, essa relação tem-se desvanecido como resultado da condição que o pai atravessa nessa fase da sua vida. Aliada à sua postura retraída, percebe-se uma letargia significativa e tristeza profunda; ele afirma ver vultos e ouvir vozes recorrentemente. Destacam-se isolamento social, abulia e indiferença perante situações com que se depara no seu quotidiano. Paralelamente, demonstra crescente autofocalização das temáticas (a sua associação a um investimento comercial que o levou à ruína), com ideações paranoides recorrentes.

\section{Método}

\section{Procedimentos}

Trata-se de um trabalho original, desenvolvido no âmbito da consulta psicológica do serviço de psicologia de um centro de saúde na zona rural do norte de Portugal, e selecionado como proposta de estudo de caso pela sua relevância clínica em torno da organização de personalidade esquizoide e depressividade associada e pela pertinência do processo psicoterapêutico. A metodologia desenvolvida ao longo do processo psicoterapêutico tem uma atitude não diretiva, à luz da Abordagem Centrada na Pessoa, com a pretensão de conhecer melhor a vivência de João a fim de facilitar o crescimento pessoal com vista a uma tendência atuali- 
zante. Foi estabelecido contrato terapêutico com periodicidade específica e duração de cada sessão. Todos os dados pessoais do paciente foram salvaguardados, assim como todas as questões éticas inerentes ao processo; foi obtida aprovação para o desenvolvimento e para a divulgação deste trabalho.

A exploração do caso e a elaboração do diagnóstico foram realizadas tendo em conta a análise da história clínica da paciente e o recurso a meios auxiliares de diagnóstico, nomeadamente o SCL-90-R Hopkins Sympton Distress Checklist 90 - Revised (SCL-90-R), uma escala de autoavaliação que oferece um método quantitativo de análise do indivíduo, facultando, dessa forma, uma abordagem valiosa do vivenciar psicopatológico. Posteriormente, foi hipotetizado um diagnóstico que constitui um suporte a fim de metodizar o objetivo da terapia. O processo de intervenção passou pelo acompanhamento individual de forma a desenvolver o sentido de realidade e de solidez interna de João. Os resultados reportam a análise compreensiva da problemática de João e ainda o desenvolvimento do processo terapêutico. O estudo é finalizado com a discussão e a conclusão do processo, com destaque para os processos inerentes ao acompanhamento e suas limitações.

\section{Motivo do encaminhamento e pedido de acompanhamento}

João é encaminhado para a consulta de psicologia clínica pelo médico de família com a descrição seguinte: "Paciente depressivo com humor triste de longa data (negativista) com repercussões a nível familiar, ao que acresce perturbação do sono". O pedido de encaminhamento foi feito pelo próprio paciente, que apresentou queixas relativas ao seu estado de humor e acrescentou que se encontrava muito triste, o que Ihe impedia de fazer suas tarefas diárias com motivação e de fazer projetos de vida futura. Desse modo, pretende-se realizar uma avaliação a fim de aprofundar conhecimentos em torno da vivência de João e traçar uma proposta de intervenção terapêutica.

\section{Participante}

João é o filho mais novo de uma fratria de 7 irmãos. Seu nascimento foi de parto normal, em casa, sem complicações evidentes. A infância é descrita por ele como algo "normal" (sic), sem qualquer tipo de problemática, sendo considerada uma etapa feliz da sua vida. João relata um percurso escolar adaptativo sem dificuldades de aprendizagem, tendo completado o ensino secundário, isto é, finalizado o $12^{\circ}$ ano. A adolescência foi vivida em Portugal, e foi salientada uma diversidade de relacionamentos interpessoais, o que estabeleceu uma época de namoros. João ressalta que nessa fase conheceu uma pessoa por quem nutria um grande sentimento, no entanto, por oposição dos pais dela, o relacionamento nunca se desenvolveu. Destaca-se ainda na adolescência um episódio significativo: João, aos 13 anos de idade, por motivo de conflito acentuado com a mãe devido à oposição dela a um relacionamento amoroso que ele mantinha, espetou uma faca em seu próprio peito, sendo imediatamente hospitalizado. Quando abordado como se sentiu com essa situação, ele refere: "eu gostei de ver o sangue ir contra a parede... sim, eu gosto de ver sangue... ainda agora, sobretudo quando mato porcos, ver o sangue a escorrer-me pelos braços, dá-me prazer..." (sic). Aos 18 anos de idade, emigrou para a Suíça e desempenhou a atividade de jardineiro. João refere ser muito empenhado, dedicando-se bastante ao que gosta: jardinar. Nesse período, conheceu sua atual esposa, depois de dois anos de trabalho na Suíça. Após um período de namoro, João e sua mulher decidiram morar juntos. Sublinha, no entanto, que foi "mais um casamento por conveniência" (sic), acrescentando que "não era um amor louco" (sic). Durante o período de oito anos na Suíça, conseguiu obter recursos financeiros significativos que lhe permitiram melhorar sua qualidade de vida. Após esse período, regressou a Portugal por vontade da mulher. Nessa fase de regresso, teve uma filha, e, mais tarde, casou-se pela igreja. O casamento, segundo João, foi por conveniência, uma vez que havia por parte da filha uma grande vontade de que os pais se casassem. Fica patente, a partir daí, um relacionamento que se adivinha com algumas dificuldades. 
Em Portugal, João aponta uma situação relevante que terá ocasionado o desenvolvimento de parte do seu desconforto atual: uma relação de sociedade comercial que, de acordo com ele, levou-o à ruína. João e o sócio traçam um projeto em comum: abrir uma loja de tintas. A loja esteve aberta ao público por um período de dois anos. Esse período da sua vida é encarado com muita revolta e angústia, e, sobretudo, foi pautado pela raiva. Na sequência dessa sociedade, João cessa a atividade e entra em litígio legal durante 2 anos, culminando na decisão do tribunal que decreta o pagamento das dívidas em conjunto com o sócio. Ao longo desse processo, João é internado no serviço de psiquiatria no Hospital de Vila Real, durante 15 dias, por vivenciar uma ansiedade e revolta constante que o leva ao isolamento permanente e a ameaçar de morte sua esposa. Quando se aborda esse assunto, ele afirma que foi um ato isolado e que não voltou a ameaçá-la. Com esse episódio, sentiu que estava fazendo algo negativo e que não estava totalmente consciente dos seus atos. Depois da alta médica, João refere apresentar dificuldades de ordem psicológica, financeira e familiar. Sente revolta, pois perdeu a poupança guardada ao longo do seu percurso laboral. Descreve "um recomeçar do zero" (sic), embora com uma postura ativa, pois volta para a Suíça onde permanece 5 anos e economiza para pagar as dívidas. De acordo com João, foram tempos muito difíceis, quando ele se limitou apenas à atividade laboral: "era casa trabalho, trabalho casa" (sic). Em relação a esse último regresso a Portugal, João ressalta suas dificuldades pessoais, que ocasionam três episódios de internamento no serviço de psiquiatria do Hospital de Vila Real, com um significativo isolamento social e um crescente de dificuldades em relacionar-se, ao que se acrescem ideações suicidas.

No momento da consulta, João tem 55 anos de idade, está desempregado, elabora escassas perspectivas futuras, às quais se alia a falta de recursos financeiros, que lhe impossibilita de ter a vida que sempre desejou. João desenvolve pensamentos recorrentes e persistentes acerca da dívida e da pessoa que, de acordo com ele, conduziu-o a essa condição. Culpabiliza-se constantemente, de- recorrência a pensamentos suicidas. Aponta dificuldades no desenvolvimento de atividades no período da manhã, o que inclui sair da cama, fato que suscita revolta para consigo mesmo. Além disso, a relação com sua atual esposa é conflituosa. Considera a filha um pilar na sua vida, apesar de pensar que, nessa fase, não tem investido na relação.

\section{Avaliação psicológica}

A partir do fato de que desde os primeiros momentos é desenvolvida uma atitude de ajuda genuína, torna-se menos pertinente dividir de forma linear a fase de avaliação da fase da intervenção, visto que elas podem operar como um continuum. No entanto, destacamos, nessa primeira fase, uma necessidade de conhecimento e de devolução ao utente. Paralelamente, utilizaram-se meios auxiliares de diagnóstico. Sob esse ponto de vista, a avaliação nas primeiras sessões foi assinalada por uma exposição de João diante de sua problemática, quando, para além de serem percebidas suas preocupações atuais, foi-lhe dado um espaço para falar sobre si. Tendo em conta suas dificuldades atuais e os comportamentos em relação a si próprio e aos outros, torna-se imperativo mencionar seu humor triste, sua lentificação motora, sua falta de sono e sua ideação suicida constante.

A falta de contato ocular por parte de João e a presença de desconforto diante de uma exposição pessoal deram lugar à necessidade de explanar o objetivo do espaço de consulta e de abordar ainda a confidencialidade. Numa fase inicial, foi importante encorajar João à livre expressão dos seus sentimentos, quando o psicólogo aceita, reconhece e clarifica os sentimentos negativos que são expostos em consulta (Rogers, 1974). Após a compreensão por parte de João da sua pertença do espaço, percebe-se que gradualmente expõe seus sentimentos. Após a coleta de dados referentes à história clínica, bem como a compreensão do pedido de João, fica patente uma compreensão empática e o estabelecimento de uma relação terapêutica mais próxima. Todavia, de acordo com a informação recolhida, suscitaram-se algumas dúvidas acerca da 
organização vivencial de João em torno das problemáticas, pelo que se recorreu à administração da SCL-90-R, uma escala de autoavaliação que oferece como método quantitativo de análise do indivíduo uma abordagem valiosa do vivenciar psicopatológico.

Os resultados da aplicação dessa escala corroboram algumas das hipóteses levantadas após a coleta anamnésica. Evidenciaram-se pontuações significativamente elevadas na subescala obsessão, somatização, hostilidade, culpa e depressão. Essas foram as 5 subescalas mais evidenciadas, descritas por ordem decrescente, com destaque maior à obsessão. Essa informação coaduna-se com os conteúdos evidenciados no decorrer das primeiras sessões, com destaque para um pensamento constante do seu passado, que interfere de forma sistemática no presente, "até posso ter outros pensamentos, mas a minha cabeça funciona como uma bola de pingue-pongue, quando dou por ela, já estou a pensar no sócio que me lixou a vida" (sic). O cariz ruminativo desses pensamentos que versam seu passado impossibilita João de investir em projetos futuros. Nessa medida, durante 15 anos, João não elabora qualquer perspectiva laboral, o que se traduziu numa depressividade continuada, levando-o a um adoecer psicológico. A depressividade, segundo Matos (2007), surge sempre que há a existência de um duro e contínuo conflito com objetos introjetados, conduzindo o indivíduo a uma constante condição de esmagamento do self e esgotamento do eu. Revela-se uma dimensão constante da personalidade, assemelhando-se àquilo que se designa de neurose.

Por outro lado, fica perceptível uma elevação da pontuação da subescala somatização. Almeida (2006) e Lázaro e Àvila (2004) apontam que a depressão está associada a queixas somáticas no paciente. Os estados psíquicos como ansiedade e depressão acarretam prejuízos ao organismo (Volpi, 2005) As pessoas com sintomas somáticos revelam-se mais ansiosas e deprimidas, com níveis mais altos de alexitimia e com maior dificuldade em controlar as emoções (Almeida, 2006; Volpi, 2005), o que vai ao encontro dos níveis significativamente elevados na escala Hostilidade. João sublinha episódios de ansiedade extrema: "às vezes enervo-me muito e apetece-me partir tudo"; " às vezes não berro mais alto, porque tenho vizinhos, senão..." (sic), ao que acresce um sentimento de culpa permanente.

\section{Resultados}

\section{Diagnóstico psicológico}

O conhecimento mais profundo de João sugere um funcionamento pautado por uma depressividade arrastada ao longo do tempo. Os dados inicialmente aportados davam-nos conta de um humor triste, acompanhado por uma lentificação motora e anedonia, o que equaciona a associação a uma possível patologia depressiva. Todavia, ressaltam-se ainda na vivência de João características particulares de misticismo, autocentração e isolamento significativo diante do exterior. Ele desenvolve ideações paranoides significativas que se enfatizam em episódios emocionalmente difíceis para ele e condicionam sua estabilidade emocional e a projeção de planos futuros. Destaca-se uma vivência pautada pela revolta e pela injustiça, canalizada de forma agressiva para consigo e para com terceiros. Essa questão vai ao encontro dos dados obtidos na avaliação psicométrica, com destaque para um cariz obsessivo e hostil para além da somatização, o que contribui para sua indisponibilidade laboral. No seguimento da avaliação, percebem-se em João alterações de pensamento de relevo, pelo que recria uma imagem de si que oscila entre a sobrevalorização e uma desvalorização pessoal pautada pela culpa e sentimento de ineficácia (na sustentação e suporte da família). Paralelamente, desenvolve alterações da percepção, nomeadamente alucinações auditivas e visuais ("vozes" (sic) que falam com ele e sombras que o seguem), o que Ihe confere uma possível perturbação da personalidade esquizoide com patologia associada - depressão. Os sujeitos denominados esquizoides parecem indiferentes às relações sociais (Ruiloba, 2000); tal como João aponta, ele prefere ficar à margem dessas relações, inclusive rejeita sair de casa para não estar com as pessoas. 


\section{Objetivos da terapia}

O conhecimento pessoal de João deixa adivinhar uma vivência pautada pela angústia, pela revolta e pela tristeza, com ideias suicidas recorrentes. Nesse sentido, a intervenção iniciada desde logo vai ao encontro de um apoio atento e regular feito de forma semanal. João encontra-se vulnerável devido à permanente vivência de acontecimentos significativos do seu passado que o impede de realizar suas tarefas diárias com motivação. Destaca-se uma existência regulada por sofrimentos e alienação pessoal que o conduz à quebra entre 0 eu e o outro. As vozes que ouve e as sombras que vê dão-nos conta de um desenvolvimento psicopatológico ainda que não haja uma total desfragmentação do eu e que ele se mantenha em contato com a realidade. Embora desde cedo manifestasse uma significativa indiferença afetiva, parece ter havido fatores significativos ao longo do seu desenvolvimento que o têm conduzido a um processo de adoecer psicológico. Atualmente, remete-se à vivência de uma realidade pautada por ideias paranoides às quais acresce uma existência solitária que evita quebrar. Nesse sentido, tornou-se relevante realizar uma abordagem terapêutica a fim de que ele pudesse elaborar os sentimentos que o rodeiam, pensar sobre si mesmo e sobre seu potencial com vista a aceitar as dificuldades e lidar com sua situação atual. Pretendeu-se facilitar a tendência atualizante de João, reduzir conflitos internos, tensões e impulsos, com o objetivo de que ele desenvolvesse uma maior autonomia (Rogers \& Kinget 1977; Volpi, 2005).

\section{Intervenção: acompanhamento psicológico}

O processo de acompanhamento durou 7 meses, com uma periodicidade quinzenal e duração aproximada de 45 a 50 minutos por sessão. A primeira abordagem realizada com João teve o intuito de estabelecer uma relação terapêutica por meio de um acolhimento, de uma aceitação incondicional e empatia. Pretendeu-se criar um espaço de crescimento pessoal onde João desenvolvesse uma percepção positiva acerca de si próprio a fim de que pudesse agir de forma a estabelecer com êxito relações sociais mais satisfatórias (Rogers, 1974). Note-se que faz parte do cenário depressivo a postura rígida na sua severa dificuldade em reconhecer perdas/frustrações e ultrapassá-las (Grana \& Bastos, 2010). Existe também em João uma rigidez excessiva em aceitar as frustrações e as consequentes perdas. Nessa medida, João reporta-se à dor do passado, ao que acresce uma culpabilização permanente.

As primeiras sessões $\left(1^{\mathrm{a}}, 2^{\mathrm{a}}\right.$ e $\left.3^{\mathrm{a}}\right)$ foram pautadas pelo estabelecimento da empatia, nas quais o utente expõe sua vivência, e deixaram perceptível uma significativa incongruência entre o que sente e a forma como percebe sua existência diária. Tornou-se ainda pertinente esclarecer o objetivo do espaço de consulta e clarificar o pedido de ajuda. Essa fase constitui uma pré-terapia que conduz ao desenvolvimento de um sentimento de aceitação e empatia (Rogers, 1974). Ressalte-se certa dificuldade inicial no estabelecimento da relação terapêutica com João, pautada por distanciamento. Sua dificuldade define-se em termos de incoerência entre o querer e o fazer, entre o ser real e o ser ideal. Aliada a sua postura marcadamente defensiva, existe, por parte de João, uma atitude constante de dependência e de apatia, o que faz com que ele participe de forma ativa apenas quando solicitado. Essa questão foi sendo contornada na medida em que João foi progressivamente recriando um clima de aceitação incondicional. Desta feita, torna-se relevante ressaltar a libertação de si, com maior abertura à experiência, com vistas a promover $\mathrm{O}$ desenvolvimento das suas potencialidades com vistas ao funcionamento pleno, em que João seria capaz de experimentar e de aceitar plenamente seus pensamentos, reações e sentimentos, e se deixasse guiar pelas inúmeras alternativas para assegurar uma satisfação mais completa de si (Rogers \& Kinget, 1977). A primeira abordagem realizada por João diz respeito às queixas referentes ao seu estado de humor: ele dizia sentir-se constantemente triste e letárgico, o que o impedia de cumprir sua rotina com motivação e evidenciava a falta de objetivos perante a vida. Ele apresenta ainda dificuldades no 
nível relacional, fato que o incomoda significativamente. Atribui a culpa não a si, mas às pessoas que o rodeiam, nomeadamente sua esposa, seu pai e seus amigos. Embora seu pedido seja a modificação do seu humor e do seu projeto de vida, ele apresenta uma total desresponsabilização de si: "eu não posso mudar as pessoas que estão ao meu redor" (sic). Ao encontrar-se numa condição de estagnação, percebe-se certa dificuldade em considerar outras capacidades e perspectivar outras opções de vida. Dessa forma, o posicionamento do depressivo ocorre por meio do incessante desejo de libertação de um aprisionamento psíquico que o incomoda (Neto et al., 2011).

A quinta sessão deu lugar a um espaço de devolução da compreensão realizada em torno de João, com destaque para uma vivência angustiada diante do passado e certa intolerância com o presente. João encontra-se significativamente voltado para si, prisioneiro de pensamentos perseverativos de ruína fundamentados na interpretação que tem vindo a articular da sua experiência pessoal. Destaca recorrentemente episódios referentes à perda ocasionada quando do seu regresso da Suíça, todavia fica patente certa indiferença afetiva precoce, nomeadamente nas relações parentais e na atual ligação com a esposa, que de resto é desvalorizada por João. Ao longo dessa sessão, João atribui pouco significado à relação conjugal, sentida como vazia e em grande parte pautada por conflitos. Ao mesmo tempo, suscita em si certa agitação diante do medo de perda da única relação que parece recriar em si um contacto interpessoal mais próximo, nomeadamente a relação com a filha. Foi devolvida a João a percepção de uma perda continuada que tem vindo a sentir em todos os domínios da sua vida, todavia parece existir em si uma necessidade de travar essa sensação ainda que essa questão se dirija na sua maior parte para a figura da filha. João verbaliza uma clara necessidade de proximidade com a filha, o que oscila com um sentimento de ineficácia e de culpabilização pelo fato de estar pouco presente emocionalmente e no que concerne ao suporte econômico. Nessa medida, foi proposto a João o desenvolvimento de um trabalho pessoal voltado para a compreensão de si e da gestão emocional dos senti- mentos que incapacitam sua atualização. Tucci, Corrêa e Dalben (2011) destacam que os pacientes que apresentam depressão revelam os piores resultados nas relações familiares. Portanto, um ambiente familiar permeado de sentimentos negativos parece funcionar como um fator estressante. Ainda nessa sessão, para além da abordagem da problemática, João deu conta de alguma desorganização percebida no que concerne aos seus hábitos diários, nomeadamente no padrão de sono e de alimentação. João não apresenta um sono regulador e reparador devido ao fato de ficar horas indeterminadas a ouvir rádio durante a noite. Na alimentação, faz apenas duas refeições diárias. Nesse sentido, devolveu-se a importância de modificar hábitos a fim de facilitar a aquisição de um bem-estar físico e psicológico. Estellita-Lins, Oliveira e Coutinho (2006) sublinham a relevância de modificar a vida diária sempre que existe um prejuízo real e surgem implicações secundárias no bem-estar.

Aquando da sessão sete, João introduz novos dados relativos a sua vivência, nomeadamente um episódio que aponta como significativo: "na Suiça, mandei matar o meu sócio... eu tinha muita revolta dentro de mim" (sic). Denota um forte sentimento de injustiça e revive ainda hoje um desejo de vingança, ainda que não concretizado, canalizando o seu mal-estar numa ideia recorrente de perda. Percebe-se um desacordo entre o eu idealizado e a experiência vivida. Em consequência da necessidade de consideração positiva de si, João percebe sua experiência em função das condições às quais ele veio submeter-se, realizando uma percepção seletiva (Rogers \& Kinget, 1977). As experiências surgem dessa forma deformadas ou interceptadas, gerando um sentimento de desarmonia que recria um estado incongruente. O plano traçado acabou por não suceder por insistência da esposa. Note-se que, diante dessa questão, João manifesta certo arrependimento pelo fato de não ter concretizado um cenário de vingança, todavia oscila numa postura de reflexão em torno do que poderia acarretar para si: "oh claro, que depois até penso que iria viver pior do que agora" (sic). Essa questão parece corroborar-se já que um ano depois desse episódio o sócio falece por doença: "Deus fez a sua justiça" (sic), fato que não colmata a an- 
gústia sentida. É devolvido a João que a reflexão acerca da vivência de alguns episódios significativos têm-no levado a encontrar incongruências entre aquilo que viveu e o que sente atualmente, pelo que parecem existir questões muito pessoais capazes de condicionar seu crescimento pessoal. $\mathrm{O}$ trabalho realizado junto do paciente parece dirigir-se para uma necessidade pessoal de aceitação e, acima de tudo, não culpabilização de si; independentemente das escolhas menos positivas realizadas, "o único facto importante para a terapia são os sentimentos que o paciente é capaz de exprimir na situação" (Rogers, 1974, p.259). Fica patente uma depressividade em torno da experiência de João, com características próprias e formas de estar que constroem uma personalidade ao longo dos anos. Entretanto, devolve-se a importância de se direcionar para o presente, a fim de avançar ou rumar para um caminho que ficou interrompido durante muitos anos, e ressalta-se a importância de se desenvolverem estratégias pessoais para ultrapassar esse episódio. Note-se que não é imperativo saber onde o adoecer psicológico começa ou o porquê, mas sim como ele se verifica, com que função se passou a representar e quais os modos de minimizar ou terminar com a dor (Lemos \& Cavalcante Júnior, 2009). Ao terminar a sessão, percebe-se em João que esse espaço é considerado gradualmente como seu, onde sente que pode expor seus problemas de forma natural e voluntária, com destaque para a ênfase na relação terapêutica que se manifestou no seguimento das demais sessões.

Na sessão oito, verifica-se uma viragem significativa na forma de estar e sentir de João: ao invés da anterior anedonia, há um maior entusiasmo nas pequenas coisas, como passear, trabalhar, estar e conversar com a família. Ele faz questão de mencionar, ainda que de forma absorta consigo mesmo, "eu até liguei para uns amigos que não ligava há muito, e gostei de falar com eles" (sic). Tal como refere McIntyre, Barroso e Lourenço (2002), existe uma importância em variáveis relacionadas ao suporte social, que trazem repercussões nas emoções. Ainda que se possa dizer que João tem apresentado melhora e que tem demonstrado modi306 ficação em alguns comportamentos - "tenho pas- sado melhor as semanas" (sic) -, este é um trabalho gra-dual, que requer por parte de João um esforço árduo e motivação constante para a mudança, mas é indubitável sua melhora em determinados aspectos da vida. De acordo com Rogers (2009, p.108), "um dos elementos da terapia que mais recentemente tomamos consciência é o quanto ela representa para o utente a aprendizagem de uma aceitação plena e livre, sem receio dos sentimentos de outra pessoa". Julgamos que esse não terá sido um processo imediato, todavia parece constituir uma referência na abertura que João faz a si mesmo. Sentimos que a sessão anterior poderá ter sido libertadora para João na medida em que ele pôde falar abertamente do seu desejo de vingança: ainda que não concluído, parecia não ser o cerne da resolução do seu conflito interno. O crescimento pessoal passa então pelo conhecimento de si, dos seus desejos, fantasias, da sua aceitação e resolução interna. Percebemos um João, ainda que confuso, menos defensivo e mais disponível.

A sessão dez é marcada por um conínuo de revelações em torno de si. João sente-se agora mais disponível para abordar questões pessoais que assolam seus pensamentos. Contrariamente àquilo que inicialmente teria dito, João teve várias vezes internado no hospital, nomeadamente no serviço de psiquiatria, fato que se reporta ao seu regresso definitivo da Suíça. Aborda esses internamentos de forma vaga, demonstrando expressamente através do seu discurso e da sua postura o incômodo em falar desses episódios, todavia ressalta que foram fases difíceis e das quais guarda sentimentos desagradáveis, pois se sentia muito só e desolado. Fica patente uma percepção de destruturação do eu, e, desde então, acresce um incremento de sintomatologia psicopatológica - pensamento paranoide -, para além de uma significativa apatia, abulia e autocentração. Nessa sessão, João aporta um dado relevante que desde logo se revela significativo na compreensão da sua forma de estar. Relata um episódio ocorrido aos 13 anos de idade, em que espetou uma faça no peito. Essa foi sua primeira tentativa de suicídio. Convém salientar que existiram mais duas tentativas de suicídio já na fase adulta, uma por enforcamento e outra por excesso de 
fármacos. Todas essas tentativas não foram consumadas: o paciente acreditava que existira dentro de si nesses momentos uma força que o empurrava para a vida. Quando explorado o motivo da sua primeira tentativa de suicídio, ressalta a oposição da mãe ao seu namoro. Justifica esse ato pelos conflitos desenvolvidos com a mãe, manifestando vontade de pôr término à vida. Ressalte-se a vivência descrita por João a respeito desse episódio: "eu até gostei de ver o sangue ir contra a parede...deu-me gozo..." (sic). A adolescência é caracterizada por muitas mudanças que ocorrem no mundo do adolescente tanto físicas quanto cognitivas e psicológicas. Em virtude dessas transformações, os aspectos emocionais na adolescência são instáveis, culminando muitas vezes em estados depressivos ou até tentativas de suicídio. No início da adolescência, o suicídio é ainda visto com certa imaturidade e inexorabilidade. Todavia, mais adiante, a presença de distúrbio psiquiátrico pode favorecer o comportamento suicida, e os conflitos familiares não resolvidos aumentam seu risco (Avanci, 2004). Ao longo dessa sessão, há uma compreensão mais profunda de João, que experimenta desde cedo sentimentos de revolta pessoal e instabilidade afetiva. Percebe-se ao longo do seu percurso desenvolvimental uma forma de estar particular, criada pela percepção das vivências imbuídas de sentimentos de rejeição e ideações paranoides que mais recentemente se têm vindo a acentuar. Portanto, o processo de reabilitação tem como objetivo manter um acompanhamento dos utentes na comunidade, orientando-os para o aperfeiçoamento de certas habilidades e proporcionando-lhes uma maior autonomia (Silva, 2011).

A sessão 12 marca a interrupção deste seguimento terapêutico por razões externas. Todavia, foi proposta a continuidade desse processo por um outro profissional, ao que o utente mostrou receptividade.

Iniciando a sessão, há a necessidade por parte do utente de explanar os episódios de alucinações que tem vindo a vivenciar. Refere ver sombras que são acompanhadas por vozes. Quando explorado o tipo de vozes, o que lhe dizem e como interferem na sua vida, João refere que ouve vozes que cha- mam por ele. Quanto às sombras, não consegue decifrar o que são. Todavia, refere "eu não me importo disso, se me importasse, estava tramado..." (sic). Contudo, note-se que é um assunto relevante para ele, já que o expôs em consulta e que, de alguma forma, o incomoda. Esse é um aspecto que compromete a vida do paciente, que pode tornar-se mais frágil perante situações de vulnerabilidade.

\section{Discussão}

Fica perceptível por parte de João uma ansiedade permanente que equivale a uma tomada da consciência latente do conflito que permanece entre o eu e sua experiência. De acordo com Rogers e Kinget (1977, p.170), " ...a angústia constitui a reação do organismo a um estado de desacordo e ao perigo da tomada de consciência - que exigiria uma modificação da estrutura do eu".

Torna-se importante realizar uma associação ao seu percurso desenvolvimental, que, embora descrito por João como um percurso normal, paradoxalmente, é assinalado por algumas perdas (relações afetivas) e por uma instabilidade emocional que culmina na automutilação aos 13 anos de idade. Patenteia-se um funcionamento muito autodirigido e modelado por gostos pessoais relacionados com o sangue e a morte, destacando-se certa bizarria ("gosto de ver o sangue a escorrer pelos meus braços" (sic)). Entretanto, o fato de emigrar para a Suíça traduz um empenho acrescido e um investimento laboral significativo, ao mesmo tempo em que se destaca uma relação amorosa pautada por pouca proximidade emocional e que finda num casamento descrito como conveniente.

Posteriormente, ele ressalta um fato que parece ter recriado em João uma quebra afetiva que culmina em episódios de descompensação e que faz com que ele seja internado por motivo de ideações suicidas recorrentes. Desde então, a vivência na Suíça passa a ser considerada uma prisão para si. Essa vivência de raiva e injustiça constantes cria uma vivência de si e dos outros pouco positiva. Embora tenha mantido a atividade laboral na Suíça, podemos suspeitar de uma vivência assinalada pela exaustão emocional, que acarreta episódios 
recorrentes de descompensação (pensamento de morte do sócio) e um desconforto mantido até hoje, vivenciado através da sua bizarria (sente o cheiro da morte), da sua desvalorização significativa e ainda da vivência de fenômenos místicos com alucinações auditivas e visuais.

Desse modo, parece tomar forma, à medida que as sessões decorrem, a ideia de uma vivência pautada por uma patologia da personalidade esquizoide. Como refere Ruiloba (2000), os indivíduos esquizoides estão à margem da estrutura sociofamiliar, parecendo viver em si mesmos e ausentes, como que com a atenção permanentemente dirigida para as vivências internas que os afetam de forma significativa. No entanto, resulta um pensamento próximo do primitivo e do mágico: "eu espero pelo dinheiro que o homem me roubou..., ele há-de aparecer" (sic). A particularidade maior da personalidade esquizoide é usar como eixo de sobrevivência preferencial a relação de objeto subjetiva, privada, pessoal, restrita à sua área de onipotência, e habitar, unicamente quando estritamente inevitável, a relação do seu falso self com a realidade externa. Isso porque o esquizoide pode dominar, ainda que precariamente, a formação de um mundo subjetivo, que é aquele que assume naturalidade e Ihe parece real. A grande dificuldade constitui o fato de recriar um mundo subjetivo fechado na sua realidade, que se assume precária em contato com o mundo real. Nessa medida, o desenvolvimento de João parece ter ficado cercado e estagnado no tempo, o que impossibilita seu crescimento pessoal. Ao mesmo tempo, fica patente uma depressividade que se estende pelo seu percurso de vida. A depressividade "traduz-se num vago sentimento de inferioridade e num comportamento de relativa incapacidade, revelando um esforço defensivo contínuo para não se deixar deprimir" (Matos, 2007, p.47). Desse modo, julgamos que a vivência de João não é pautada propriamente por uma depressão: o que domina seu estado afetivo não é a tristeza e o senti-mento de perda, mas sim um sentimento de opres-são e de dependência, uma disposição depressiva que caracteriza a depressividade e não um estado de humor (Matos, 2007).

Como nota final, embora o processo tenha

308 sofrido uma interrupção nessa fase, percebe-se ainda um trabalho importante a ser realizado uma vez que é ainda evidente uma dificuldade pessoal de João em aceitar suas vivências. Diante do cariz psicopatológico que encerra sua experiência diária, julga-se que seria pertinente uma abordagem multidisciplinar capaz de colmatar sintomatologia positiva, que João descreve com mais ênfase nos últimos tempos. Reitera-se a necessidade de prosseguimento do tratamento; através da intervenção psicológica, espera-se que, ao vivenciar toda essa dor e ao expressá-la através de palavras, abordando o sofrimento, e confirmando que a dor psíquica traz uma aprendizagem deveras enriquecedora, conseguirá adquirir uma real libertação de si.

Ao concluir este trabalho, é importante deixar claro que interpretar a alucinação como a própria manifestação do mundo real do sujeito é uma tarefa fundamental para uma intervenção psicológica. Considerando-se que a saúde ou a doença irrompe em uma determinada localização histórica, é fulcral não esquecer a história de vida de João, e sim enquadrá-la e compreendê-la na sua própria biografia, com o intuito de auxiliá-lo no seu percurso muitas vezes vivenciado no limiar da realidade.

Embora o processo tenha sofrido interrupção, percebe-se ainda um trabalho importante a ser realizado, todavia não se possa deixar de verificar algumas melhoras notáveis ao longo do processo terapêutico realizado com o paciente. Assim sendo, João mostra uma maior motivação no seu quotidiano. O utente refere ter vontade de falar com as pessoas, demonstra uma maior disponibilidade em querer cultivar a relação com a filha e demonstra igualmente vontade de ter um emprego, uma vez que se encontra na condição de desempregado. Aliado à sua crescente causa nos pequenos passos diários, cumpre a tarefa de não estar permanentemente sozinho, manifestando comportamentos cada vez mais sociais, ainda que isso constitua algum esforço pessoal. Fica patente em João uma vontade de libertação que julgamos estar em crescente processo e que, posteriormente, poderá corresponder a uma atualização de si ao aceitar sua vivência passada e presente. Como limitações desta investigação, têm-se as características do próprio 
estudo, uma vez que é uma análise de caso na qual os resultados obtidos não devem ser generalizados para a população em questão. Todavia, são trazidos resultados importantes acerca do funcionamento interpessoal de uma estrutura esquizoide de personalidade, o que pode trilhar caminhos pertinentes para investigações futuras.

\section{Referências}

Almeida, F. (2006). Depressão e somatização. Revista Portuguesa de Psicossomática, 6(1), 87-91.

Avanci, R. (2004). O adolescente que tenta suicídio: estudo epidemiológico numa unidade de emergência (Tese de mestrado não-publicada). Universidade de São Paulo.

Estellita-Lins, C., Oliveira, \& V., Coutinho, M. (2006). Acompanhamento terapêutico: intervenção sobre a depressão e o suicídio. Psychê, 18(10),151-166.

Grana, L., \& Bastos, A. (2010). Vulnerabilidade social: o psicodiagnóstico como método de mapeamento de doenças mentais. Psicologia Ciência e Profissão, 30(3), 650-661.

Lazzaro, C., \& Àvila, L. (2004). Somatização na prática médica. Arquivos de Ciência Saúde, 11(2), 2-5.

Lemos, P., \& Cavalcante Júnior, F. (2009). Psicologia de orientação positiva: uma proposta de intervenção no trabalho com grupos em saúde mental. Ciência \& Saúde Coletiva, 14(1), 233-242.
Mclntyre, T., Barroso, R., \& Lourenço, M. (2002). Impacto da depressão na qualidade de vida dos doentes. Saúde Mental, 5(4), 13-24.

Matos, A. C. (2007). A depressão (2ª ed.). Lisboa: Climepsi Editores.

Neto, M. L., Reis, A. O., Vasconcelos, C. A., Lima, N. N., Cartaxo, J. S., Ferreira, M. L., et al. (2011). Histórias de vida sobre o fenómeno depressivo. Arquivos Brasileiros de Ciência da Saúde, 4, 155-159.

Rogers, C. (1974). Psicoterapia e consulta psicológica. Lisboa: Morais Editora.

Rogers, C. (2009). Tornar-se pessoa. Lisboa: Padrões Culturais Editora.

Rogers, C., \& Kinget, G. (1977). Psicoterapia e relações humanas (Vol 2). Belo Horizonte: Interlivros.

Ruiloba, J. A. (2000). Introducción a la psicopatología y la psiquiatria (4a ed.). Barcelona: Masson.

Silva, T. M. (2011). Apoio e cuidado da família de pacientes com esquizofrenia. Uningá Review, 2(3), 70-78.

Tucci, A. M., Corrêa, F. K., \& Dalben, I. (2001). Ajuste social em pacientes com transtorno afetivo bipolar, unipolar, distimia e depressão dupla. Revista Brasileira de Psiquiatria, 23(2), 79-87.

Váldes, M. (2000). Transtornos de personalidad. In J. V. Ruiloba. Introducción a la psicopatología y la psiquiatría (4 ed.). Barcelona: Masson S.A.

Volpi, J. (2005). Quando o corpo somatiza os conflitos da mente. Centro Reichiano, Psicologia Corporal, 1-3.

Recebido em: 4/4/2012

Versão final em: 27/6/2012

Aprovado em: 16/7/2012 
